\title{
RECUPERAÇÃO PAISAGÍSTICA E AMBIENTAL DO VALE DO RIO PAÚBA: ESTUDOS PARA UM PLANO DE ESPAÇOS LIVRES
}

ROBBA, Fabio

Arquiteto pela Universidade Mackenzie, Doutor em Estruturas Ambientais Urbanas pela FAUUSP, Especialista em Arquitetura Paisagística pela IFLA/Fupam.E-mail: frobba@terra.com.br

\section{RESUMO}

Esse trabalho é parte da monografia final desenvolvida para o Programa de Capacitação de Professores de Arquitetura Paisagística (IFLA/Fupam). Como um exercício de projeto de planejamento da paisagem, buscou-se desenvolver uma proposta para um mosaico territorial para o Vale do Rio Paúba, no município de São Sebastião, litoral norte de São Paulo.

O Vale abriga um pequeno vilarejo cuja vocação nos últimos anos tem se voltado para o turismo de veraneio, como todas as praias que existem neste trecho da costa do Estado. No entanto, as condições geomorfológicas do território pressupõem uma fragilidade do ecossistema que ainda não foi considerada ao longo de sua ocupação.

Atualmente, a região encontra-se em estágio intermediário de ocupação e degradação, porém, ainda existe a possibilidade dessas condições de devastação e impacto ambiental serem minimizadas e até certo ponto revertidas, por isso houve o interesse e a necessidade de desenvolver o trabalho.

A proposta foi pautada no desenvolvimento econômico e social da comunidade e na busca por melhores condições ambientais, paisagísticas e sociais para potencializar a vocação turística da região. Para tanto, foram utilizados princípios e conceitos da Ecologia da Paisagem em sintonia com propostas de desenvolvimento econômico e integração social.

\section{Palavras-chave: Ecologia, ambiente, planejamento.}

\begin{abstract}
This paper has been written as a final work for the Brazilian Capacity Building Programme for Landscape Architecture. It is a teorical exercise for land planning based in a proposal for Paúba River Valley at São Sebastião district located in the north shore of São Paulo State.

In the valley there is small village that has a growing vocation for tourism as all the region surronding, but their geographic conditions dictates a ecological fragility that has been misunderstood during in its urban occupation.

Nowadays, the area is in intermediate level of urbanization and environmental degradation but it is still possible to stop or minimize this process of ecological damage. The plan is based at the economic and social development of the community and at the search for better environmental and social conditions to increases the local potential. The principles and theories of Landscape Ecology has been used at this plan.
\end{abstract}

Keys words: Ecology, environment, planning.

\section{Introdução}

Usando os conhecimentos, métodos e informações adquiridos no Programa de Capacitação de Professores de Arquitetura Paisagística, este exercício de projeto, foi desenvolvido de modo a esboçar um plano de espaços livres para o Vale do Rio Paúba, localizado no município de São Sebastião. 
Essa proposta conceitual foi pautada no desenvolvimento da comunidade e na busca por meIhores condições ambientais, paisagísticas e sociais, pois a região encontra-se em um estágio intermediário de degradação com possibilidade de reversão deste quadro.

Mesmo tendo conhecimento que um trabalho dessa envergadura necessitaria de uma equipe multidisciplinar para desenvolvê-lo a contento, julga-se que o fato de estar refletindo sobre a área, mesmo que de modo hipotético, poderia detonar um saudável processo de reflexão.

Imagina-se dar continuidade esse plano apresentando-o para representantes do Poder Público local, das associações amigos da vila e de organizações não-governamentais, para, primeiro incrementá-lo aceitando contribuições de profissionais de outras disciplinas e, depois, encaminhá-lo para instituições que tenham poder de ação e possam fazer algum uso dele.

\section{Contexto: meio físico}

São Sebastião é dos quatro municípios (Caraguatatuba, Ilhabela e Ubatuba) que compõem - Litoral Norte do Estado de São Paulo. O município faz divisa, ao sul, com o município de Bertioga, que por sua vez pertence à Baixada Santista, e, ao norte, com Caraguatatuba. Sua peculiaridade reside no fato de estar em uma região de relevo muito acidentado onde os mares de morros da Serra do Mar se debruçam sobre o oceano diferindo do município de Bertioga cujas planícies costeiras são bem mais amplas.

A região toda tem características geomorfológicas expressivas, compreendendo duas zonas distintas:

- Baixadas e planícies litorâneas descontínuas e de pequenas dimensões

- A Serra do Mar e um conjunto de morros e morrotes costeiros contínuos e extensos que se debruçam sobre o mar.

A Serra do Mar é formada por um frontão serrano de rochas ígneas e metamórficas com fortes declividades e altitudes variadas. Esse frontão que é a borda do Planalto Atlântico, apresenta-se como muralhas profundamente recortadas pelos rios e córregos que avançam sobre o oceano. Da Baixada Santista e até a Praia de Barra do Una tal muralha está afastada da orla criando largas planícies costeiras. Daí em diante, a Serra aproxima-se da costa formando um cotovelo recortado, no qual pequenas praias são separadas por morros, morrotes (extensões da serra), esporões e divisões de águas. $\bigcirc$ contato desses esporões com o mar forma os costões que mergulham no oceano.

O cotovelo na linha da costa é formado pelo promontório da Serra que adentra o oceano em direção ao sudeste e que mergulha no mar, erguendo-se, logo em seguida para formar a grande Ilha de São Sebastião, a Ilhabela; depois do canal, a serra volta a recuar formando a maior planície do Litoral Norte que chega até o município de Caraguatatuba.

Essa condição geomorfológica cria na costa do município de São Sebastião uma paisagem de rara beleza com faixas de areia cercadas por morros verdejantes e pela muralha da serra do mar proporcionando pontos de visuais amplos e belíssimos.

A Praia de Paúba localiza-se no meio da linha da costa do cotovelo que forma o promontório do canal da llhabela, e está ladeada por dois morros, extensões da Serra, e, a leste, confinada pela própria Serra. Sua planície costeira é de pequenas dimensões e está localizada entre a faixa de areia e a Rodovia Rio Santos (SP-55). A partir da pista de rolagem começa um trecho de relevo mais acidentado que se conecta ao Parque Estadual da Serra do Mar.

Existe ainda uma outra peculiaridade na Praia de Paúba. Os recortes da serra caprichosamente serpenteiam de modo que a praia se volta para oeste, e, diferentemente da maioria 
das praias da costa brasileira, Paúba tem o pôr do sol no mar, fato que encanta e surpreende os freqüentadores.

Ao sul, na praia, deságua um pequeno Rio Paúba, que esculpiu o vale. O rio nasce na Serra, no Planalto do Juqueriquerê e corre entre os morros da ponta do Toque-Toque e do Sagim, tendo dois trechos característicos, a parte serrana com o leito de pedra e águas cristalinas e, logo após a ponte da rodovia, começa o trecho de planície, onde ele é mais sinuoso e tem o leito arenoso. $\bigcirc$ rio, principal fonte de abastecimento do vilarejo, encontra-se medianamente limpo contaminado por alguns lançamentos de esgoto proveniente de casas e condomínios de veraneio que despejam seus dejetos no rio sem tratamento.

No canto sul da praia as condições marinhas de dispersão não são favoráveis, pois ali se configura o final de uma enseada e as correntes marinhas não colaboram para dispersão das águas. Devido a essas condições, já houve períodos que a balneabilidade da praia ficou seriamente prejudicada.

Os morros que envolvem lateralmente Paúba estão parcialmente desmatados, desconectando a Serra dos costões, e a única unidade de conservação que está legalmente garantida na área é o Parque Estadual da Serra do Mar, à leste.

A fauna e a flora do vale região são típicas da Mata Atlântica Meridional aparentando ser conjunto homogêneo, porém as interações entre os fatores físicos e biológicos geraram uma série de sub-ecossitemas, perceptíveis em um olhar mais aprofundado, que caracterizam a grande heterogeneidade e biodiversidade da área. Encontra-se desde ecossistemas terrestres sob forte influência marinha, como praias, mangues e restingas até florestas de encostas e de altitude, passando pelos ecossistemas de planícies costeiras e alagáveis. Toda essa variedade de unidades de paisagem são uma dádiva para o vilarejo, mas mesmo tempo, representa um delicado equilíbrio a ser preservado e, portanto, a manutenção e a recuperação desses sistemas naturais se faz urgente.

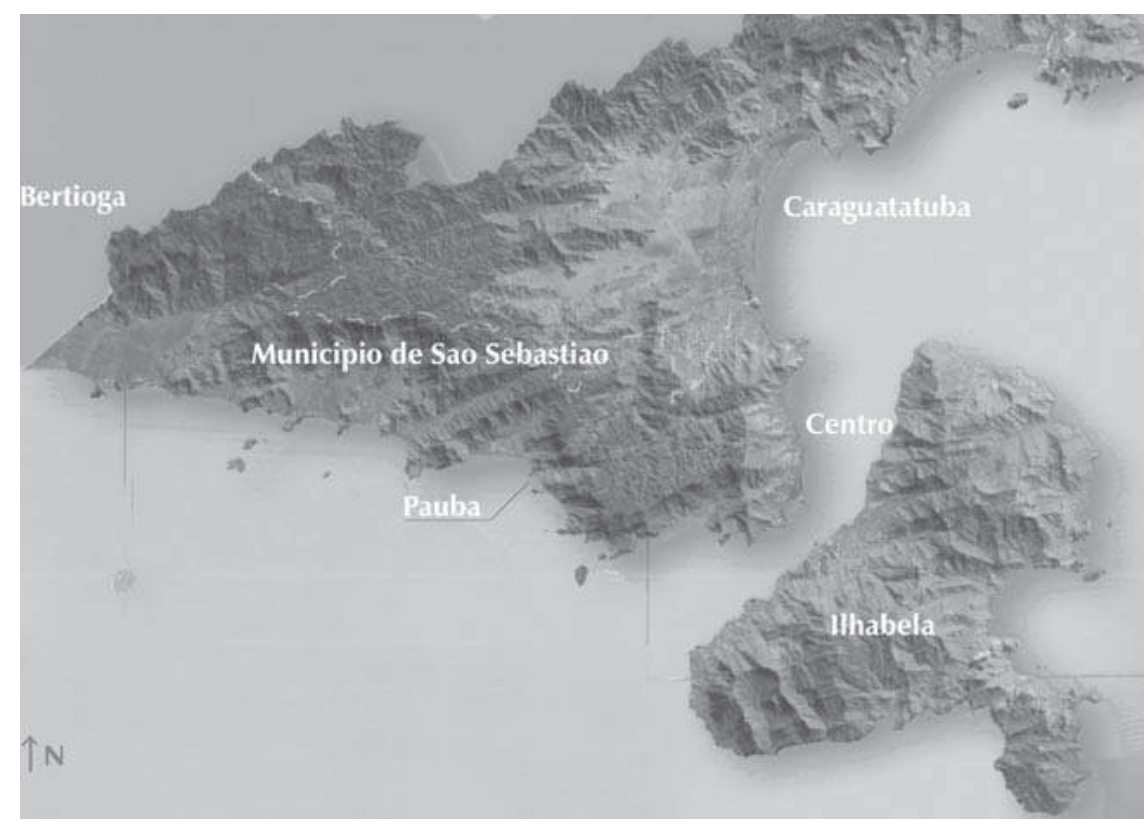

\section{Contexto: ocupação recente}

A ocupação do Litoral Norte foi impulsionada em meados do século XX pela abertura das estradas que conectaram a costa com o planalto. As condições de revelo dificultaram a implantação dessas ligações rodoviárias, deixando a região bastante isolada até o terceiro quartel do 
século XX. A Rod. Rio-Santos, no trecho de São Sebastião, por exemplo, somente foi asfaltada em meados dos anos 1980.

Na Praia de Paúba, a partir dos anos 1970, além da ocupação da comunidade caiçara local, passou a existir uma ocupação de segundas residências para veraneio. Nesse tempo, o desenvolvimento dos transportes rodoviários proporcionou para parte da população dos grandes centros, principalmente São Paulo, a facilidade nos deslocamentos em busca de refúgios para férias e descanso em paisagem menos consolidados e belos como as praias do Litoral Norte.

Inicialmente o vilarejo de Paúba era procurado por pessoas que buscavam lugares isolados e que tinham bastante 'espírito de aventura' pois o acesso era precário e a infraestrutura primitiva.

Com a finalização do asfaltamento da Rod. Rio-Santos nos anos 1980, houve uma explosão na procura por esse litoral e uma conseqüente expansão da ocupação urbana. Começaram também a ser implantados condomínios, hotéis e pousadas já apontando para a demanda que viria a se consolidar nos anos seguintes.

Nos anos 1990 a região se ratificou como um dos principais destinos de veraneio dos paulistanos e de habitantes do interior do estado. Nesse momento a expansão urbana de todos as praias se intensificou de maneira significativa, consumindo e dilapidando vorazmente parte dos recursos naturais da região. Esse processo de urbanização atraiu para a região migrantes de várias regiões do país para atender a demanda por mão-de-obra.

Atualmente a população local mescla os nativos (caiçaras) e os migrantes, sendo que nas temporadas a população flutuante de turistas e habitantes de segunda residência aumenta muito.

Em Paúba, o processo seguiu os mesmos passos de outras praias, porém, devido a suas condições geográficas a expansão urbana ainda está em fase consolidação. A pequena planície costeira ainda não está totalmente ocupada e há uma ocupação irregular, porém pouco expressiva, nos morros.

Os impactos de todas essas transformações ao longo de não mais que trinta anos são graves, porém no Vale de Paúba ainda há a possibilidade de contenção e a reversão desses danos. Enquanto é tempo é preciso planejar e controlar essa ocupação inevitável de modo a recuperar o patrimônio paisagístico, ambiental e cultural em busca da preservação da beleza, da biodiversidade e da vocação da região.

\section{Planejamento e método: princípios básicos da ecologia da paisagem}

Para desenvolver o trabalho foi utilizado o referencial teórico desenvolvido pelos estudiosos da Ecologia da paisagem. Esse referencial teórico pareceu ser o mais adequado para trabalhar a região citada, pois se trata de uma área em expansão que conta ainda com diversos recursos ambientais e paisagísticos a serem preservados.

Os princípios da Ecologia da Paisagem podem ser aplicados para as mais diversas paisagens, pois os territórios são compostos de elementos vivos e compõe um sistema vivo. Como um organismo vivo esse sistema vivo exibe três características básicas: Estrutura, Função e Processo.

Estrutura seria o padrão espacial e o arranjo entre os elementos da paisagem, a Função seriam os movimentos e fluxos dos animais, plantas, água, vento, matéria e energia através da Estrutura. Processo seria a dinâmica e as alterações que ocorrem no arranjo na Estrutura e na Função ao longo do tempo.

A Estrutura de uma paisagem é composta três elementos básicos: manchas, corredores e matrizes. Esses elementos juntos formam um mosaico territorial. Seguindo esse método, tais elementos combinados permitem a análise das mais variadas paisagens, pois se disseca os processos 
naturais e os processos humanos e os seus impactos sobre a Estrutura e a Função. Esse padrão mancha-matrix-corredor é universal para qualquer paisagem e será a base dos comentários a seguir:

\section{O plano: princípios aplicados}

\section{Conectividade da paisagem: corredores e manchas}

As grandes manchas de vegetação nativa são as únicas estruturas da paisagem que protegem os aqüíferos e as redes de rios e córregos. Proporcionam abrigo e refúgio para espécies animais interiores possibilitando que estas se desenvolvam plenamente.

As manchas menores terão sempre uma quantidade maior de espécies fronteiriças e possibilitarão menor quantidade de habitat para espécies interiores. No entanto, as manchas menores disseminadas sobre uma matriz atuam como pontos de apoio para a circulação de algumas espécies animais e dão proteção a espécies raras que circulação ampla. No caso de estarem perto de grande mancha podem ajudar a realçar a biodiversidade e a mobilidade de espécies associadas à mancha maior.

Além de proporcionar abrigo para fauna e reforçar a biodiversidade as manchas de vegetação de qualquer porte ajudam na diminuição da velocidade de escoamento da água do deflúvio superficial colaborando significativamente no controle da erosão de terrenos com declividades acentuadas e, da mesma forma, colaboram para a filtragem desse escoamento que carrega partículas polventes que contaminariam os rios, lagos e córregos.

Analisando a região citada, observa-se que há a grande mancha de Mata Atlântica, a leste, que cobre a escarpas da Serra do Mar e que é uma Area de Preservação Permanente. Existe ainda uma série de manchas menores isoladas espalhadas pelo território entre a serra e os costões.

A Rod. Rio-Santos e a servidão do Oleoduto São Sebastião/Santos criaram uma ampla interrupção na mancha de vegetação apartando os trechos lindeiros ao oceano da grande mancha da serra. Tal interrupção diminuiu a possibilidade de interação entre áreas próximas do mar e região montanhosa limitando os fluxos entre elas o que promoveu um impacto expressivo sobre os sistemas naturais principalmente no que respeito mobilidade da fauna e diversidade de espécies animais e vegetais.

A manutenção e preservação das manchas existentes e o incremento do número de manchas existentes foi o princípio fundamental que norteou esse estudo. A definição de áreas de reflorestamento onde há campos desmatados e capoeiras, em duas etapas, deverá colaborar nesse sentido.

A topografia da área e seu regime hidrológico sugerem que as manchas de vegetação sejam utilizadas de maneira colaborar com a diminuição dos processos erosivos, estabilizando encostas e restaurando grotões existentes. Além disso, as manchas de vegetação devem proteger os corpos d'águas.

Além do tamanho e do formato das manchas de vegetação a conectividade entre as manchas tem função fundamental na manutenção de processos naturais e preservação da biodiversidade.

O isolamento e a perda do habitat é a principal causa da extinção de espécies e diminuição da biodiversidade. Vários são os processos que corroboram nesse isolamento e desaparecimento dos habitat, no entanto, o restabelecimento da conectividade entre manchas e habitat com corredores e 'stepping stones' pode favorecer a biodiversidade, principalmente em áreas de vida selvagem cujas espécies animais tem grande mobilidade. 
Da mesma forma que os corredores podem atuar com uma grande barreira ou filtros como, por exemplo, rodovias e linha férreas, a criação de faixas ou corredores de vegetação entre manchas grandes e pequenas pode recriar uma conectividade perdida em processos de ocupação que fragmentaram, seccionaram ou perfuraram habitats. Como já citado anteriormente, na área de estudo, a grande barreira criada pelo corredor da Rodovia Rio-Santos e a desconexão entre a mancha da Serra do Mar e as manchas de vegetação lindeiras ao oceano são o principal problema diagnosticado. A barreira da rodovia apesar de ser muito longa e intensa poderia ser facilmente vazada com a criação de passagens subterrâneas de pequeno e médio porte e com a implantação de 'pontes vegetadas' que passassem por sobre a pista em áreas onde existam animais de maior porte.

Essa desconexão entre o ecossistema serrano e dos costões promovida pelo desmatamento e pela ocupação humana é o ponto mais delicado a ser abordado, pois envolve ações de maior amplitude. O princípio a ser adotado no Vale do Rio Paúba seria a criação e a recomposição de faixas de vegetação que ligassem a costões à serra, para tanto seriam utilizadas áreas onde se sobrepusessem funções, por exemplo os corredores ripários e os morros.

Os corredores ripários são naturalmente importantes linhas de fluxo na paisagem e por isso a constituição de faixas de vegetação ciliar unificaria as funções de proteção do corpo d'água e da criação de um corredor de conexão costa-serra.

Já a configuração do vale, cercado por dois morros que avançam sobre o oceano induz a criação de corredores de vegetação no sentido leste-oeste de modo a ligar as pequenas manchas remanescentes em seus topos e grotas com a mancha da serra. Essas faixas também estariam limitando a ocupação urbana em áreas de alta declividade e passíveis de intensos processos erosivos, além de ajudar a preservar o patrimônio paisagístico do local.

Dessa forma, tal proposta de restabelecimento da conectividade costa-serra conduz a um desenho de faixas paralelas e alongadas de vegetação ligadas por um grande "s" caracterizado pelo corredor de mata ripária nas margens do Rio Paúba que serpenteia pela planície.

$\mathrm{Na}$ foz do rio seria necessário um alargamento dessa franja vegetal para recriar o pequeno sistema de manguezal original que foi destruído com a ocupação urbana muita próxima ao rio e à praia.

\section{Mosaico territorial: redes e matrizes}

A integridade funcional e estrutural de uma paisagem pode ser avaliada por dois critérios: a escala e o padrão.

Como já citado, a conectividade dos sistemas naturais também representa uma melhor qualidade saudável da paisagem, corredores conectados com manchas de diversos portes formam redes e matrizes que envolvem outros elementos da paisagem. As redes e matrizes enfatizam as funções da paisagem facilitando ou inibindo fluxos e movimentos através do mosaico territorial.

O planejamento territorial pode, considerando tais questões, lançar mão da criação ou articulação de redes e matriz para agregar atributos a determinadas paisagens. No entanto, redes e matrizes podem, assumir diferentes padrões quando se varia a escala de aproximação, por exemplo, um habitat fragmentado pode ser interpretado como uma mancha uniforme em uma escala maior.

162 Analisando em uma escala grande pode-se afirmar que o Vale de Paúba é ainda uma área majoritariamente coberta por vegetação nativa, principalmente quando engloba o Parque Estadual da Serra do Mar. Porém, observando-se em uma escala mais fina, nota-se que manchas aparentemente uniformes representam mosaicos territoriais diversos e instigantes. 
Em relação às áreas urbanizadas essas diferentes colorações se evidenciam.

Nos quarteirões situados entre a faixa de areia e o rio (Z1), que corresponde à urbanização mais antiga e onde havia as primeiras casas da vila, nota-se uma urbanização menos densa com menor taxa de ocupação dos terrenos e uma arborização mais regular e ampla. Tais características conferem a essa área uma aparência de mancha uniforme e uma melhor condição para abrigar parte da fauna local, principalmente pequenos animais, insetos e aves. Na faixa lindeira à praia, a vegetação típica de restinga foi dizimada e substituída por outras espécies. Visando manter e melhorar a condição ecológica dessa mancha urbana já consolidada, propõe-se o incentivo aos proprietários dos imóveis, na sua maioria moradores não locais, para algumas medidas pouco onerosas:

- O plantio de espécies vegetais (arbóreas e arbustivas) nativas.

- Plantio de espécies vegetais da restinga nos lotes lindeiros à praia, com o objetivo de criar habitat para certas espécies e preservar o aspecto da praia.

- Evitar a impermeabilização desnecessária do terreno.

- Evitar ou aumento da densidade urbana.

Na área entre o rio e a rodovia (Z2), a urbanização é mais recente, tendo ocorrido em sua maior parte depois do asfaltamento da pista sendo caracterizada por uma maior densidade habitacional e uma cobertura arbórea mais rala e fragmentada. Nesse trecho existem ainda glebas vagas que merecem atenção pois poderão ser urbanizadas futuramente com critérios pouco conscientes dos processos naturais da paisagem.

Para essa área a proposta é definir um mosaico territorial com os seguintes critérios:

- Manter e incrementar a vegetação das áreas ripárias ocupando algumas áreas remanescentes e desobstruindo algumas áreas ocupadas.

- Definir as áreas remanescentes que poderão receber urbanização (ZN).

- Definir as condições dessa urbanização, proibindo altos níveis adensamentos e impermeabilização maciça do solo.

- Estocar áreas para criação de espaços livres públicos e coletivos.

- Incentivar a arborização das vias e intra-lote com espécies nativas.

- Criar uma zona de alagados construídos para tratamentos das águas servidas do vilarejo.

- Incentivar e exigir que as edificações de maior porte, tais como condomínios horizontais, hotéis e pousadas gerenciem seus próprios resíduos e esgotos.

A leste da Rodovia Rio-Santos encontra-se a área, conhecida como sertão (Z3), onde começa a ocorrer uma urbanização esparsa ao longo da estrada que caminha paralela ao rio. Essas edificações estão na sua maioria ocupando ilegalmente áreas de proteção permanente e promovendo grande desmatamento.

A regulamentação e a contenção da expansão desse movimento de ocupação é um dos maiores desafios no vale e os critérios considerados serão:

- A definição do tipo de ocupação por chácaras e sítios para agricultura local

- Restrição e fiscalização da ocupação nas áreas de preservação permanente (junto ao rio, em áreas de vegetação nativa e no parque)

- Nas áreas próximas à rodovia a definição de áreas de interesse social (ZS) para a construção habitações populares para abrigar a população de baixa renda e migrante.

- Recomposição da vegetação nas áreas de capoeira. 


\section{Proteção dos corredores rápidos}

Os corredores ripários são naturalmente importantes linhas de fluxo na paisagem e sua proteção, por meio da manutenção de manchas de vegetação ciliares é fundamental para a manutenção da qualidade da água e de suas várzeas.

Primeiramente porque substâncias dissolvidas no deflúvio superficial, que em determinas das áreas urbanas tem a condição de um esgoto diluído, podem ser absorvidas pela terra nas faixas vegetadas. Substâncias tóxicas, tais como nitrogênio, fósforo e outras toxinas, que contaminariam as águas do canal são retidas pela rugosidade e porosidade da superfície vegetada e podem ser absorvidas por processos de bio ou fito-digestão.

Em segundo lugar as superfícies rugosas das áreas vegetadas diminuem a velocidade do escoamento das águas das chuvas evitam o acúmulo em pequenos períodos de tempo o que poderiam provocar enchentes além de diminuir o índice de carregamento de solo que minimizando os processo erosivos nas áreas de várzeas.

Como terceiro é último ponto a preservação e recomposição das matas ciliares proporciona criação de habitat para as espécies típicas de várzeas e a manutenção da qualidade das águas permitem o desenvolvimento de população de espécies aquáticas, tais como peixes e anfíbios.

A melhoria e manutenção da qualidade da água do Rio Paúba é a principal demanda a ser atingida por esse trabalho. O rio é a principal fonte de águas potável para o vilarejo e a polvição de suas águas que deságuam ao sul na faixa de areia contamina o mar e pode prejudicar a balneabilidade da praia o que traz conseqüências devastadoras para a estrutura econômica local cuja vocação é o turismo praiano e o eco turismo.

Portanto, a proteção do corpo d'água na planície e na região de montanha é imprescindível e ainda possível de ser realizada sem maiores custos ou ações.

Na planície, apesar de parte das margens já estarem ocupadas por edificações unifamiliares ou multifamiliares ainda é possível que áreas não ocupadas sejam preservadas livres para receber um plantio de recomposição da vegetação ripária. Também como o intuito de recompor esse corredor algumas ações de pouco impacto podem ser propostas:

- Incentivar os proprietários de edificações existentes a minimizar a ocupação na faixa imediata ao rio (pelo menos 10 metros).

- Incentivar que nessas faixas sejam destruídos os muros e as edificações de porte e seja plantada vegetação nativa.

- Impedir o lançamento de esgoto no rio.

- Impedir o lançamento direto de águas pluviais no rio.

- Estabelecer com os condomínios do canto sul parceira para valorizar o rio, sua barra e o manguezal.

Em caso de ações mais drásticas podem também ser propostas a demolição de algumas edificações, ou parte delas, que estejam impedindo a constituição desse corredor ripário. Além disso, junto à ponte da planície, dois lotes poderiam ser desapropriados para a criação de um ponto de contato com rio - a Praça do Rio - um espaço livre público coletivo de visualização e desfrute das águas onde também estaria a Sede de uma Cooperativa Ecológica coordenada 164 pela população local.

Já na parte montanhosa onde as várzeas estão menos ocupadas deve-se garantir essa desocupação por meio da limitação do potencial construtivo e da restrição do uso do solo evitando construções multifamiliares e com mais de dois pavimentos. 
Para incentivar o uso eco-turístico da área cuja beleza é rara com pequenas piscinas naturais e cachoeiras, propôs-se a criação de um outro ponto de contato com o rio logo acima da Rodovia Rio-Santos, de modo a criar outro Núcleo da Cooperativa Ecológica que servisse de apoio para a atividade de turismo ecológico, por exemplo, de onde partiriam as excursões para as trilhas e passeios guiados ou onde seria possível tomar um agradável banho de cachoeira.

Por fim, outra grande questão com relação á preservação das águas é o fazer com as águas servidas do vilarejo?

A Vila de Paúba não gera esgoto contaminado por águas residuais de processos industriais apenas águas residuais de utilização doméstica e comercial por isso a questão do esgoto não é tão dramática quanto em outras localidades.

No entanto, não havendo sistema de coleta de esgoto, a maioria das casas atualmente possui um sistema de fossas ou, por mais lamentável que isso possa parecer, despeja esgoto in natura no rio.

As residências unifamiliares de baixa ocupação, em geral, não representam problemas para a contaminação das águas subterrâneas com suas fossas, porém, hotéis, pousadas e condomínios representam focos maiores de geração de esgoto. Essas edificações, em geral, possuem sistemas de tratamento de esgoto, tais como estações de tratamento e fossas sépticas, no entanto, nem sempre tais sistemas são adequadamente mantidos e operados, o que pode, e até já causou, acidentais ambientais. Algo que beira o incompreensível, pois, esses estabelecimentos que seriam os maiores interessados em manter a qualidade ambiental da praia para usar isso como atrativo para clientes e conseqüentemente gerar receita são os responsáveis pelos maiores problemas de polvição.

Desde de 2005 está sendo implantado um sistema convencional de coleta e tratamento de esgoto que certamente beneficiará o vilarejo No entanto, essa solução de engenharia elaborada tem um alto custo para sua construção e para sua manutenção além de ser uma estrutura de menor visualização e conscientização ambiental.

Esse sistema coletará o esgoto de todo vilarejo que por sua vez será levado até a área além da rodovia onde está sendo construída a estação de tratamento. Depois tratada, a água será devolvida ao rio. Para vencer o desnível necessário, existirão cinco pontos de visitação e elevação até a estação. Tais pontos terão de consumir energia elétrica para funcionar o que traz um ônus energético. Além disso, nos pontos de visitação podem ocorrer extravasamentos na época de chuva o que representaria um grave acidente de contaminação.

Por essas razões, o plano propõe, como um exercício de desenho e planejamento a criação de uma área de alagados construídos cujo intuito será tratar as águas servidas do vilarejo. Os alagados construídos combinam as funções ecológicas, recreativas e estéticas pois além de promoverem a limpeza das águas, a criação de habitat para espécies nativas, são espaços que podem ser utilizados para a recreação, a educação ambiental e são sistemas naturais belos e verdejantes

No caso estudado, um sistema de coleta acionado por gravidade levaria o esgoto até a área das lagoas numa região de baixada junto do morro sul e lá, aproveitando o potencial de reciclagem da natureza da Mata Atlântica, um processo de fito e biorremediação e digestão se encarregaria de limpar a água que seria devolvida depois para o rio.

Além disso, a criação desses alagados teria uma função de conscientização população usuária e local, pois seria uma estrutura a céu aberto e visível representando a complexidade dos impactos da ocupação humana. Um terceiro Núcleo da Cooperativa Ecológica do vilarejo poderia ser instalado junto dos alagados para garantir sua manutenção e incentivar a conscientização ambiental e utilização como espaço de lazer. 


\section{Gente: vocação e potencial}

Conforme citado ao longo das páginas anteriores a vocação da costa do município de São Sebastião é francamente o turismo praiano e ecológico. Principalmente entre o centro e a Praia de Barra do Una as condições geomorfológicas ratificam essa condição, pois as planícies espremidas entre o mar e a serra não comportam uma ocupação de alta densidade.

No Vale de Paúba, essas condições são ainda mais restritivas, pois a planície ocupável é pequena e estreita sendo que as fontes de água para abastecimento são poucas e limitadas.

Por tudo isso, fica ainda mais importante definir que essa é a vocação do vilarejo e promover a convergência dessa vocação com as potencialidades da área e com a comunidade local. Tal convergência é fundamental para que um plano como tal seja viável e a participação da população no processo é um dos pilares da estratégia do plano. Caso a população local vislumbre que ações propostas são benéficas para o desenvolvimento da comunidade e incentivadoras da sua estrutura socio-econômica trabalhará na concretização e manutenção dessas propostas promovendo um ciclo virtuoso de preservação ambiental e desenvolvimento econômico.

Para tanto, a proposta da criação de uma Cooperativa Ecológica combinando especialistas de áreas diversas e membros da comunidade local é a estratégica mais eficaz, ou seja, treinar e capacitar os habitantes para gerenciar essa cooperativa voltada para as atividade de eco-turismo, educação e controle ambiental. Os Núcleos propostos no plano até então precisarão de pessoal em suas pequenas sedes para controle e manutenção de suas atividades. Por exemplos, sugere-se algumas atividades que ficariam a cargo dessa cooperativa:

- Controle e gerenciamento do Núcleo de Ambiental de Eco-turismo no Rio Paúba.

- Controle e gerenciamento no Núcleo de Educação Ambiental dos Alagados Construídos.

- Controle e gerenciamento do Núcleo Ambiental da Praça do Rio.

- Administração de uma cooperativa de coleta de lixo reciclável, sediada na Praça do Rio.

- Administração de um viveiro de plantas nativas para plantio nas áreas propostas no plano.

- Criação de um conselho de segurança ambiental para coordenar e fiscalizar as ações propostas pelo plano, composto por representantes da população local, empresários da hotelaria e membros da população visitante.

- Promoção de eventos educativos sobre os temas ambientais.

Imagina-se que dessa forma envolve-se a comunidade fazendo-a participar de todas as etapas do planejamento e, mais relevante ainda, levando a percepção de que esta depende do ambiente para sua sobrevivência sadia. Além aproximar a elevada discussão ecológica dos temas cotidianos. Os rendimentos da Cooperativa Ecológica, por exemplo, seriam revertidos para a própria comunidade.

Talvez a utopia ultrapasse a realidade e a viabilidade dessa estratégia seja facilmente demolida por argumentos terrenos e reacionários, porém, parece ideal que uma comunidade pequena onde os próprios habitantes locais, com a anuência e respaldo do Poder Público, gerenciassem e fiscalizassem o desenvolvimento ecológico, social e econômico da região e dominassem a teoria e a técnica para argumentar com eventuais agentes externos que promoveriam qualquer tipo de desequilíbrio.

Também com o objetivo de integrar e fortalecer a comunidade local o plano propõem a criação e valorização dos espaços livres públicos de modo a incentivar a convivência e a tolerância. A população local atualmente, é composta por caiçaras e seus descendentes, migrantes, na sua maioria nordestinos e alguns habitantes metropolitanos que optaram por moram na praia. A frágil cultura mesclou as tradições trazidas pelos migrantes sendo atualmente, pouco expressiva 
e difusa. Porém, as tradições de festas populares e religiosas, como o Carnaval, Corpus Christi e Finados, se mantiveram e de modo sincrético se fortaleceram na união dos costumes.

Na vila existem duas praças, a da lgreja e a do Pôr-do-Sol além do campo de futebol e a quadra esportiva. O tratamento e a manutenção desses espaços públicos é importante para garantir essa convivência numa esfera de vida pública fortalecendo as tradições locais. Existe ainda um terreno mais a leste reservado para uma futura praça (a Praça dos Pescadores) que poderia ser objeto de projeto resultado de um processo participativo que envolvesse a comunidade e fosse coordenado pela cooperativa ecológica.

Por fim, o plano prevê ainda a preservação das bacias visuais do vale de modo a preservar a fisionomia da paisagem e a manutenção do patrimônio paisagístico do vilarejo. Na planície, as miradas em direção a leste, focando os contrafortes da serra e, ao sul, a peculiar mirada em direção ao 'Coco Loco' serão pontos que deverão permanecer desobstruídos. Em Paúba, existe ainda o caráter simbólico do 'Coco Loco', uma palmeira solitária que existe a décadas na cumeeira do morro sul e que sempre foi um marco na paisagem da vila tendo sido apelidada pela comunidade surfista - "Coco loco, sozinho no topo do morro" - sendo que até hoje, a vila também é conhecida por esse termo.

Tais marcos referenciais da paisagem (os morros, os costões e o intrépido 'Coco Loco') são parte da identidade e da herança de Paúba, garantir que essas referências não sejam obstruídas ou destruídas e sejam reverenciadas é atribuição primordial desse plano de recuperação paisagística. $\bigcirc$ mesmo vale para a inevitável paisagem proporcionada pelo horizonte marinho que visto da praia é enquadrado pelas montanhas e tem um dos mais belos ocasos da costa brasileira quando o sol toca o oceano nas tardes quentes de verão.

Os conjuntos de propostas apresentados neste artigo estão expressos graficamente nos mapas em anexo.

\section{Mapas e desenhos sobre a área}

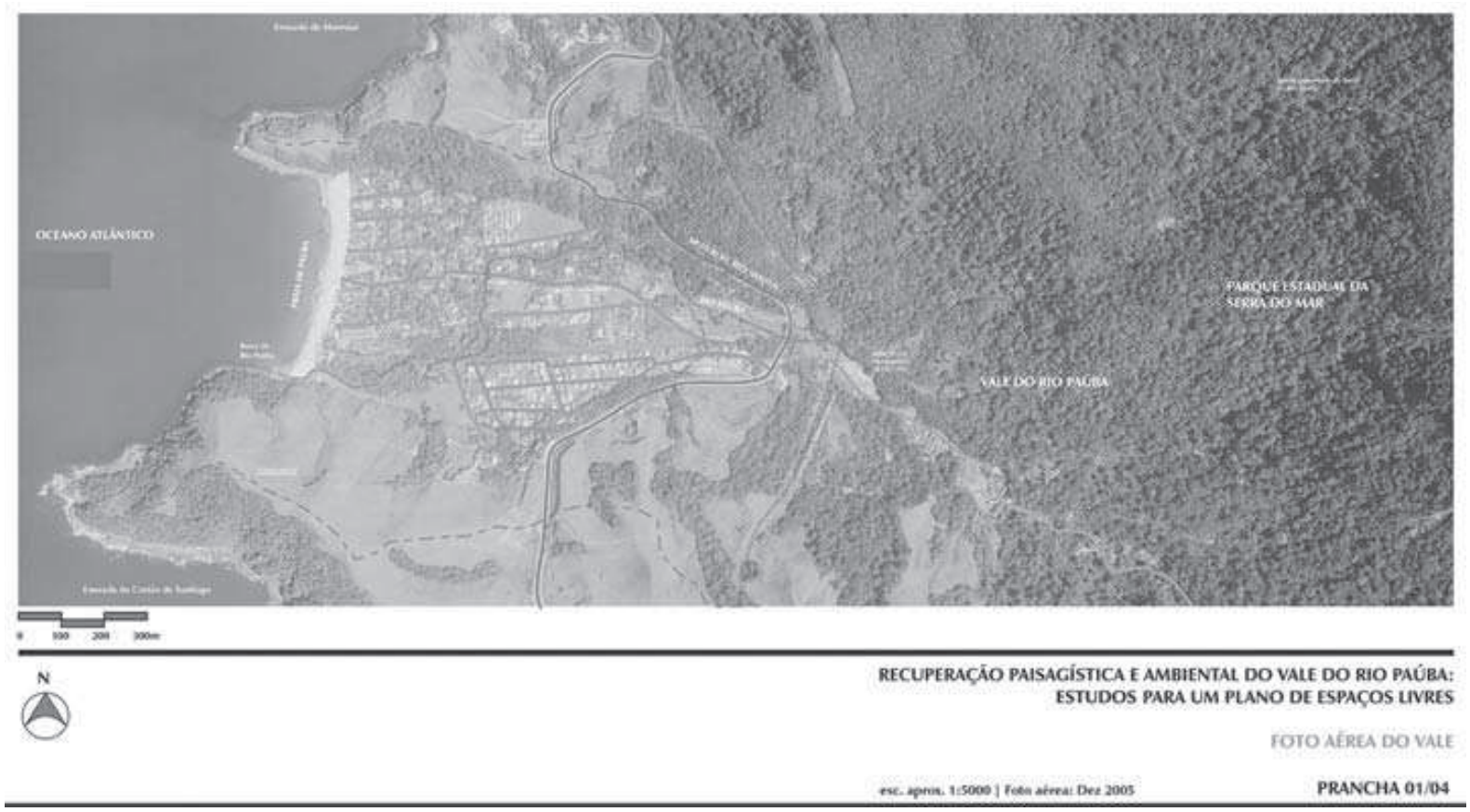

Figura 1: Foto aérea do Vale 


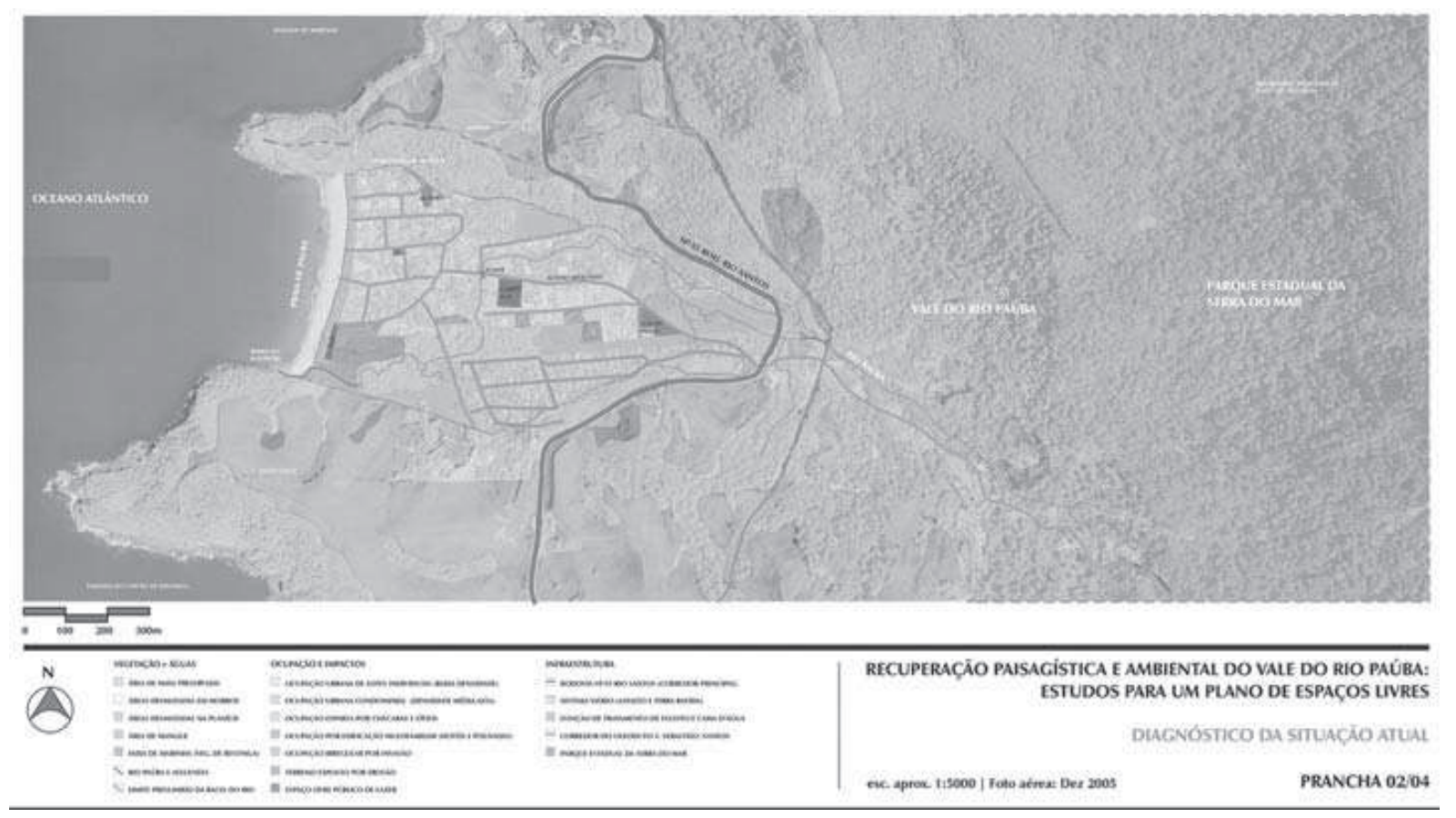

Figura 2: Mapa de diagnóstico da situação atual

\section{Planos e propostas}

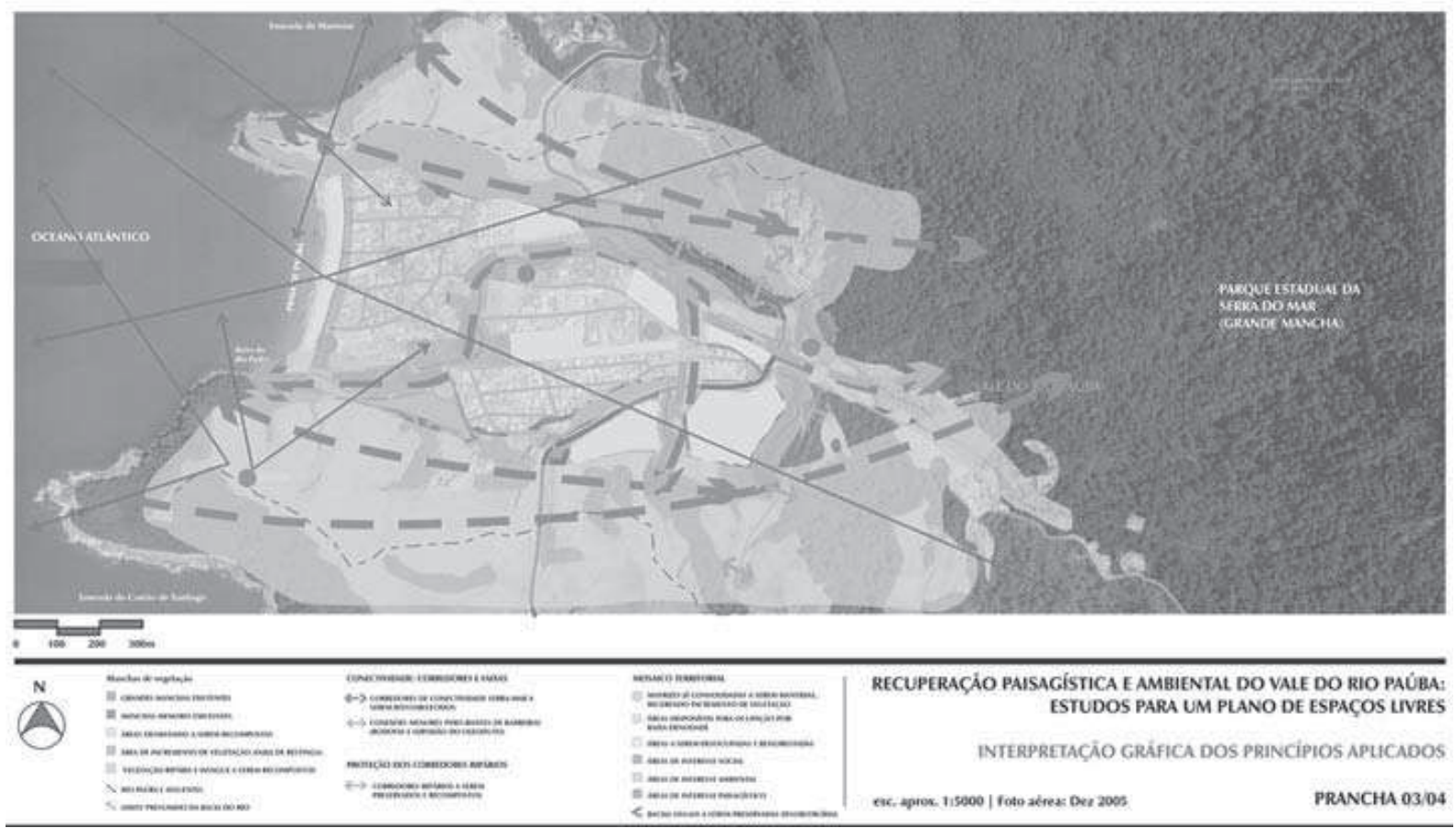

Figura 3: Interpretação gráfica dos princípios aplicados no plano 


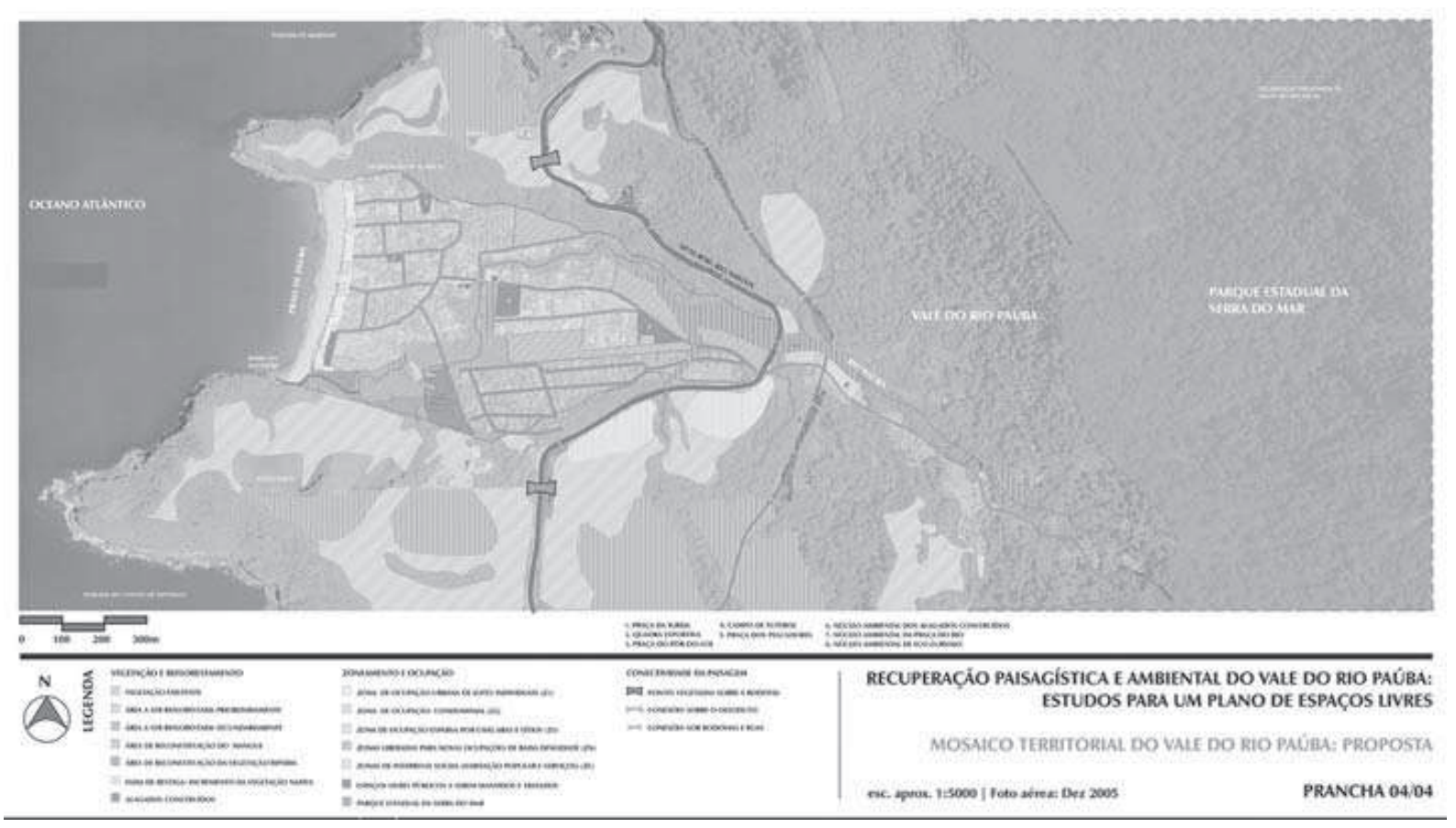

Figura 4: Mapa contendo as propostas do plano para o vale do rio Paúba

\section{Bibliografia}

AFONSO, Cintia Maria. A paisagem da Baixada Santista: Urbanização, transformação e conservação. 2001. Tese (Doutorado) - Faculdade de Arquitetura e Urbanismo, Universidade de São Paulo, São Paulo, 2001.

FABOS, J.G.; AHERN, Jonh (EE.). Greenways: The beginning of an international movement. Nova York: Elsevier, 1996.

DRAMSTAD, W; FORMAN, R. T. T.; OLSON, James D. Landscape ecology principles in landscape architecture and landuse planning. Cambridge, Island Press, 1996.

FRANCE, Robert. Wetland design: Principles and practices for landscape architects and land-use planners. Nova York: W. W. Norton. 2003.

FORMAN, Richard T. T. Land mosaics: The ecology os landscapes and regions. Cambridge Universitył Press, Cambridge: 1995.

LYLE, John T. Design for humam ecosystems. Nova York: Van Nostrand, 1985.

LYLE, John Tillman. Regenerative design for sustainable development. Nova York: Wiley, 1994.

ONU (Organização das Nações Unidas). Rio: The earth summit: Agenda 21. Rio: ONU, 1992.

The bruntland report: Our common future. Rio: ONU, 1987.

PROCESS ARCHITECTURE. Ecological landscape planning. Tóquio: Process Architecture Co. Ltd., n. 127, 1995.

SÃO PAULO (Estado). Litoral norte. São Paulo: Secretaria do Meio Ambiente/CPLEA, 2005.

SPIRN, Anne Whiston. The language of landscape. New Haven: Yale University Press, 1998.

THOMPSON, J Willian; SORVIG, Kim. Sustainable landscape construction: A guide to green building outdoors. Washington: Island Press, 2000.

SITES CONSULTADOS:

www.alnorte.org.br

www.landscape-ecology.org 